\title{
A Survey on Present Tourism in Nepal and Its Ripple Effects on Other Industries
}

\author{
Takumi Arai", Masayuki Goto \\ School of Create Science and Engineering, Waseda University, Japan
}

Copyright $(2017$ by authors, all rights reserved. Authors agree that this article remains permanently open access under the terms of the Creative Commons Attribution License 4.0 International License

\begin{abstract}
Tourism is one of the most important industries in Nepal. Based on trends, various positive impacts are realized through tourism development. The local people can also receive benefits from infrastructure development and sanitation improvement. On the other hand, there are various benefits that only people working in the tourism industry can receive. Therefore, it is necessary to identify the difference of the benefits in order to expand the ripple effects on other industries, for the further promotion of tourism development. In this research, the consciousness and opinions of local people in Nepal are investigated through a field survey, using a questionnaire. To identify the difference of consciousness across the spectrum of business activities in Nepal, the survey targeted Nepalese respondents having a variety of occupations, including those directly and indirectly connected to the tourism sector. Through the results of the field survey, the differences of the effects and the benefits by occupation are identified, and the problems of the differences and the ripple effect from tourism development on other industries are also pointed out. In conclusion, we propose the way forward for people working in various industries to receive benefits from tourism development in Nepal.
\end{abstract}

Keywords Nepal, Economic Development, Tourism Industry, Sustainability, Tourism Development, Field Survey, Ripple Effects

\section{Introduction}

Recently, the tourism industry has become an important sector in Nepal - one of the least developed countries in Asia-supporting the nation's development, and helping to transform it from an agrarian society to a more advanced society. The development of tourism has played a major role not only in the development of the economy, but in infrastructure development and sanitation improvement, all of which can benefit the local people.
However, a number of studies have identified problems in the tourism industry in Nepal [1,2]. These studies are focused on the entire tourism industry, not on the development and well-being of local communities and people, which were one of the targets, set by the government in its "Nepal Tourism Year 2011". This campaign aimed not only to acquire foreign currency by increasing tourists, but also to promote the development of infrastructure, the economy and life of the local people. These are recognized as a crucial aspect for the secondary development of the country as a whole. Nishihara et al. [3] examined the influences and problems from three aspects, including economics, environment and society. In this study, the influences of the tourism development were investigated and the difference influences between tourist spots were clarified. From this field survey, the authors suggested proposals for the government and local municipalities.

However, we thought it is necessary to maximize not only the first ripple effects from the tourism industry, but also the second ripple effects in order to further develop the nation. The first ripple effects are the benefit directly from the tourism industry and are received by people working for tourism. The second ripple effect in this study was defined as the benefit received by those who do not engage in tourism. Actually, there are large benefits for people engaging directly, but for people in other industries such as agriculture, the benefits were considerably less. Thus, in order to promote the development of the tourism industry for the country and its people as a whole, it seems necessary to identify the entire chain of stakeholders and to construct a system on which more people can receive benefits.

\section{Objectives}

In this study, we aim to identify the ripple effects, including first and second ripple effects, from tourism industry in Nepal. Therefore, we clarify the difference between those who are receiving the ripple effects and those who are not receiving it. In addition, we pick up the opinions of local people, in order to develop and support the local 
economy and environment through investigating people's awareness for the potential of the tourism industry. To achieve this goal, we designed a field survey containing both closed survey statements and open-ended questions to identify the ripple effects from the awareness of local residents. In order to know about the current situation, we introduce the framework of the three aspects of economy, society and environment, and their influences of tourism development. Hart [4] described that the quality of life should be measured by these three sectors in order to develop a sustainable community. Nishihara et al. [3] introduced this framework to investigate sustainable tourism development. Because this framework is useful to design an effective field survey, we also used the three sections to list survey statements. To identify the difference of consciousness between different occupations, the survey was targeted at Nepalese respondents working in various occupations, such as the tourism industry and farming. In this research, these respondents were stratified into three categories in terms of industries: the people working in tourism for international tourists, the people working in tourism for domestic tourists, and the people working in other industries, in particular, farming.

In addition, it is indicated that tourism branding is effective as a measure for people from other industries to benefit from the tourism industry [5]. We also included survey statements about the knowledge and consciousness necessary for branding. The actual situation of the Nepalese tourism industry was clarified by the statistical analysis by the field survey responses. Finally, we proposed the way for people working in various industries to receive the benefits from tourism development in the future.

\section{Literature Review}

This study, we aim to identify the ripple effects, including first and second ripple effects, from tourism industry in Nepal. The novelty of this research is to examine the difference between the first ripple effects and the second ripple effects to people engaged in tourism and other industries in Nepal. Many researches related to the tourism industry in Nepal have been conducted. For example, the studies by analyzing opinions of local residents about the tourism industry in various areas in Nepal are reported. Here, we overview the related works which investigated the tourism industry in Nepal from the global viewpoint and the influences of tourism to Nepalese residents.

Regarding the researches on tourism in Nepal, for example, D. N. Sutihar et al. [6] focused on the problem of predicting the number of tourists to Nepal. They estimated a formula to predict the number of tourists in next year using databases such as the numbers of tourists and the growth rates in the past. In [7], K. R. Dhakal analyzed tourists' purposes, length of stay and visited places in Nepal. By summarizing the data related to tourism in Nepal which a large number of public institutions such as the Nepalese government and the ministry of culture provided, the general overview of such as tourists' visiting periods and their purposes was clarified. Based on the opinion of tourists, K. R. Dhakal concluded that the friendly policy of the local residents and the joint effort of the Nepalese government are important. These are studies on the way of development of the tourism industry which were discussed from the viewpoint of tourists. In [8], J. Poudel focused on the influences on the traditional culture and lifestyle of local residents by the tourism industry in tourist spots near national parks. The interview survey in [8] found that traditional culture was lost and the values of residents were modernized. This phenomenon also occurs in similarly characterized areas, and then they concluded that cultural assimilation is occurring. There are also many studies on the massive earthquakes that occurred in 2015. For example, $\mathrm{H}$. L. Ghimire [9] focused on a sightseeing spot and researched how they can recall tourists to Nepal. It was concluded that it is important to initially invite people from neighboring countries such as India and China to fully appeal the tourism features of each village. Also, in [10], R. R. Kunwar et al. focused on the influence on heritage such as a temple which is a major tourism resource of Nepal. They concluded that there is enormous damage on traditional heritages, so it is necessary to promote the living heritage of the city as tourism resources.

In addition, one study by Apollo [11] focuses on the environmental and economic impacts of tourism industry to local residents, in sightseeing spots near Himalaya. Based on the results of the interview survey, this paper clarified essential issues, for example, to enhance the quality of natural tourism resources, to keep traditional culture away, and so on. This research contributed to clarify the effective guidelines, especially environmental aspect for local administration from the opinion of the residents. On the other hand, Anup et al. [12] focused the participation attitudes of local residents to the tourism industry in a trekking sightseeing spot. As a result, it was revealed that a difference in participation awareness to tourism is depending on material status, household size, and educational level. They concluded that the educational program to tourism industry is effective for gender empowerment of women on tourism development. As above discussion, there are many studies focusing on residents' consciousness for tourism industry in Nepal. However, there are no studies that clarified the secondary ripple effect from the tourism industry.

In addition, there are many researches that conducted field surveys around the world to clarify the influence of tourism on residents. For example, a method for systematically grasping the ripple effect based on mapping [13] was proposed by aggregating free-writing questionnaires. A survey to measure the influence of the tourism industry of local residents and to discuss the new findings is also reported [14]. In [15], the authors proposed a method to systematically capture the consumers' perceived value in tourist spots by analyzing numerical values through a questionnaire survey.

As described above, the research on the influence of the 
tourism industry on local residents in each area were conducted. However, these studies mainly focused on the overall overview and the difference between the first and second ripple effects targeted in this research has not been studied.

\section{Method of the Field Survey}

In order to identify the ripple effects of tourism development, we developed an interview questionnaire to investigate the current situation, as well as people's consciousness concerning the tourism industry in Nepal. By using the interview questionnaire, we conducted a field survey with a team of 35 people, consisting of Nepalese and Japanese university students. Nepalese students carried out the interviews in Nepalese, translating the responses to English. The research was conducted in sightseeing spots and rural villages near the capital city of Kathmandu from March 2 to 8, 2015. Through the method of random sampling, we interviewed a total of 226 people.

The questionnaire we developed was composed of six sections:

Section 1: Basic information: such as sex, age, place, job, profession, caste or ethnic background, duration of residence

Section 2: Questions about life change in and the effect from tourism

In order to develop the questions in Section 2, we made positive and negative effects from three important aspects: economy, society, and environment (Table1). We investigated the changes in local people's lives regarding these three aspects.

Section 3: Questions about the knowledge received from tourism development
The purpose of this section was to determine whether local people have appropriate knowledge to receive the ripple effects. It is important to aim at local product branding as a way to receive more ripple effects from tourism development. Section 3 was composed of eight questions.

Q1: Your hometown has special local products for tourists.

Q2: Your hometown has sightseeing spots or culture appealing to tourists.

Q3: You know which countries or areas the tourists in your area come from.

Q4: You know what attracts most tourists to your area.

Q5: You know what kinds of food grown in your area are mostly preferred by the tourists.

Q6: You know about the quality of food grown in your area.

Q7: You know the phrase "local product branding" well.

Q8: It is important to make "local products branding" for tourism development.

Section 4: Questions about the ripple effect of tourism local people receive

We asked what kind of benefit and damage local people get from tourism development.

Section 5: Questions about what people think about the ripple effect from tourism

Section 6: Questions about the requirements needed to benefit from tourism development

Section 7: Questions about whether tourism development is welcomed or not.

This questionnaire included both the five-point Likert scale method and open-ended questions. In Section 2, 3 and 7 , the five-point Likert scale was used. Table 2 shows the degrees of SD method used in this research. In Section 4 and 5 , the open-end questions were used to investigate the opinions of locals directly.

Table 1. Questionnaire contents in Section 2

\begin{tabular}{|c|c|c|}
\hline & Positive influences & Negative influences \\
\hline Economic viewpoint & $\begin{array}{l}\text { 1. Your family income has increased. } \\
\text { 2. The infrastructure has developed. } \\
\text { 3. The supply of electricity, water and gas have } \\
\text { been developed. } \\
\text { 4. Other industries have been developed. } \\
\text { 5. Products have increased }\end{array}$ & 5. Prices have increased \\
\hline Social viewpoint & $\begin{array}{l}\text { 6. Cultural exchanges has increased } \\
\text { 7. Sanitation has been improved } \\
\text { 8. The Quality of life has improved }\end{array}$ & $\begin{array}{l}\text { 9. Population increase and congestion have been improved. } \\
\text { 10. Traditional culture has started to disappear }\end{array}$ \\
\hline $\begin{array}{l}\text { Environment } \\
\text { viewpoint }\end{array}$ & $\begin{array}{l}\text { 11. Your knowledge and awareness on } \\
\text { protecting the environment has been increased. }\end{array}$ & $\begin{array}{l}\text { 13. The forest sites have been decreased } \\
\text { 14. The wild animals have decreased. } \\
\text { 15. The water quality has deteriorated. } \\
\text { 16. The landscape visibility, e.g. scenery, view of mountains, etc., } \\
\text { has deteriorated. }\end{array}$ \\
\hline
\end{tabular}


Table 2. The statements in the SD method

\begin{tabular}{|c|c|}
\hline+2 & Strongly Agree \\
\hline+1 & Agree \\
\hline 0 & Unsure \\
\hline-1 & Disagree \\
\hline-2 & Strongly Disagree \\
\hline
\end{tabular}

\section{Results and Discussion}

We targeted a total of 226 respondents both male and female in six areas, including shop keepers, restaurant employees, and others. The data were stratified into three categories in terms of industries. The first category represented the people working in tourism for international tourists, hotel staff, restaurant employees and shop keepers. The second category represented the people working in tourism for domestic tourists, including hotel staff, restaurant employees and shopkeepers. The last category represented people working in other industries, in particular, farmers, and staff of local restaurants, as well as shop keepers for local people. Figures 1 and 2 show the ratio of three categories in this filed survey and ratio by sex is shown in the circle graph.

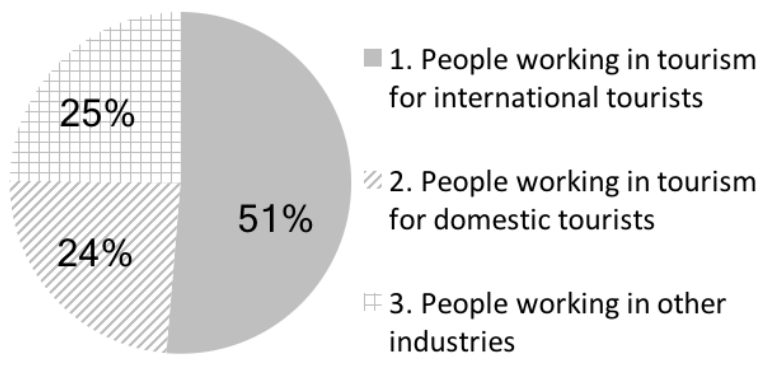

Figure 1. The ratio of three categories of all respondents

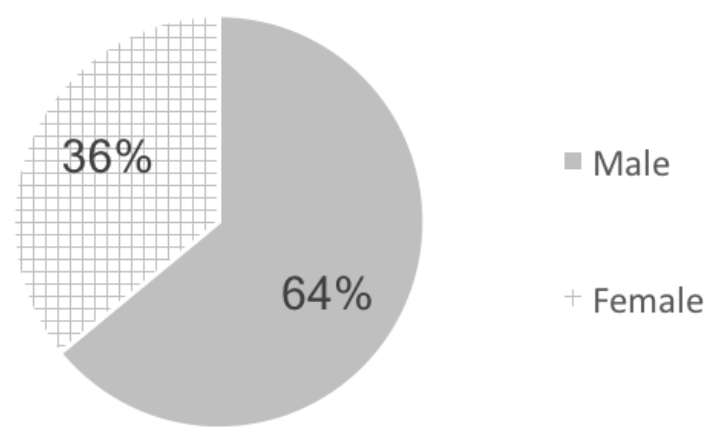

Figure 2. The ratio of sex of all respondents

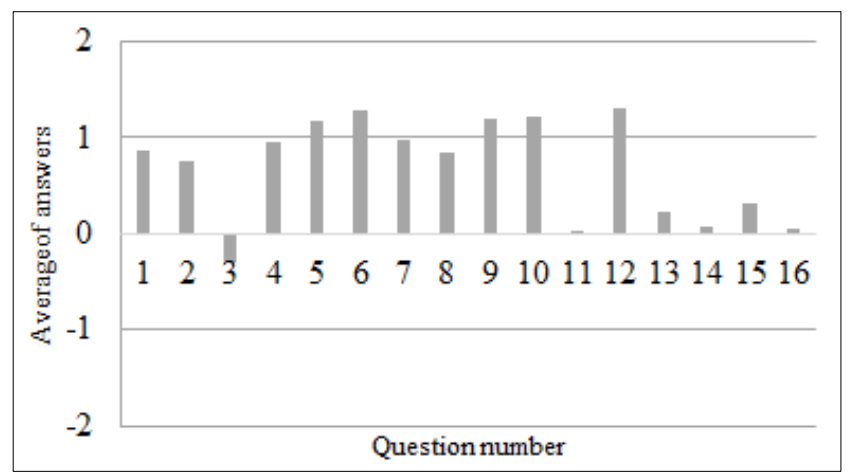

Figure 3. The average value section $2<$ about the change $>$ by all answers

Figure 3 shows the average values of each question item in section 1 asking about the change using the five-point Likert scale. The average values except for Question 3 are above 0 , that is, the trend of all people. Only this question indicates a negative value; therefore, the respondents do not feel that the infrastructure has been sufficiently development through tourism development. The following are results analyzed by stratification into three categories in terms of industries. Figure 4 shows the results analyzed by stratification into three categories in terms of industries.

As an overall trend, there are no significant differences in the average scores between categories. This suggests that the Nepalese people are feeling the impact of tourism development, regardless of their jobs. The people working for other industries are feeling the changes of their society similar to people working in tourism. In addition to the overall trend, we analyzed the differences of the ripple effects between categories. It was expected there would be many differences in the average values between tourism and other industries. It is pointed out in Question 3 and 6 which indicate the difference of the average between people working in tourism and in other industries. Based on Question 3, which asks about the sufficiency of the supply of electricity, water, and gas, the average value of international tourism is lowest because it is sufficient to live in the sightseeing spots for international tourists, but it isn't sufficient to carry on international tourism. Question 6 asking about the price increases of goods and products. The results indicate that the average of the domestic tourist business is the lowest; that is, the prices haven't increased in the tourist resorts targeting domestic tourists, because the infrastructure is not yet developed there. 


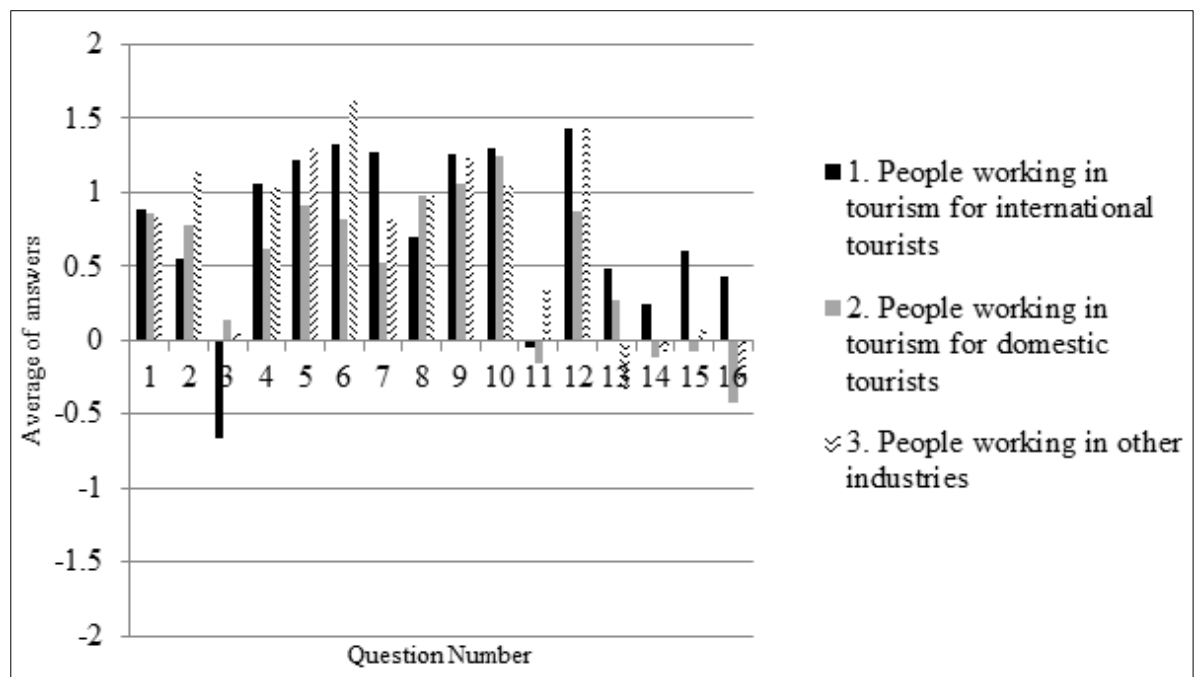

Figure 4. The average value section $2<$ about the change $>$ when we stratified into three categories

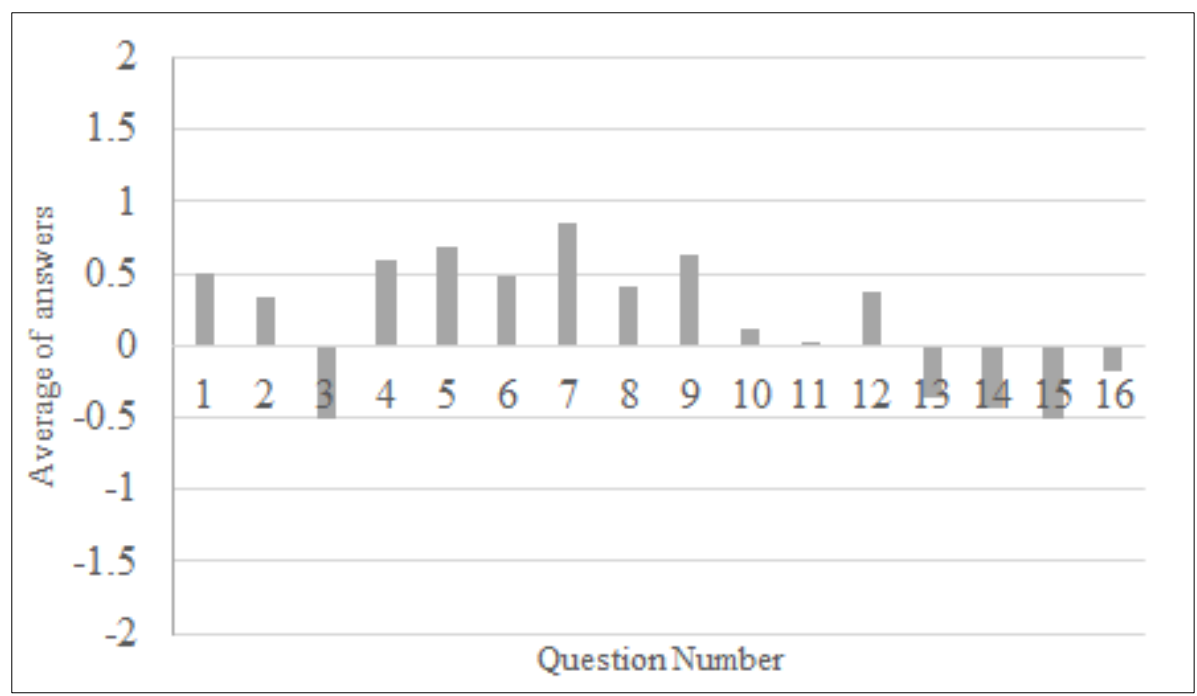

Figure 5. The average value section $2<$ it is effect from tourism $>$ by all answers

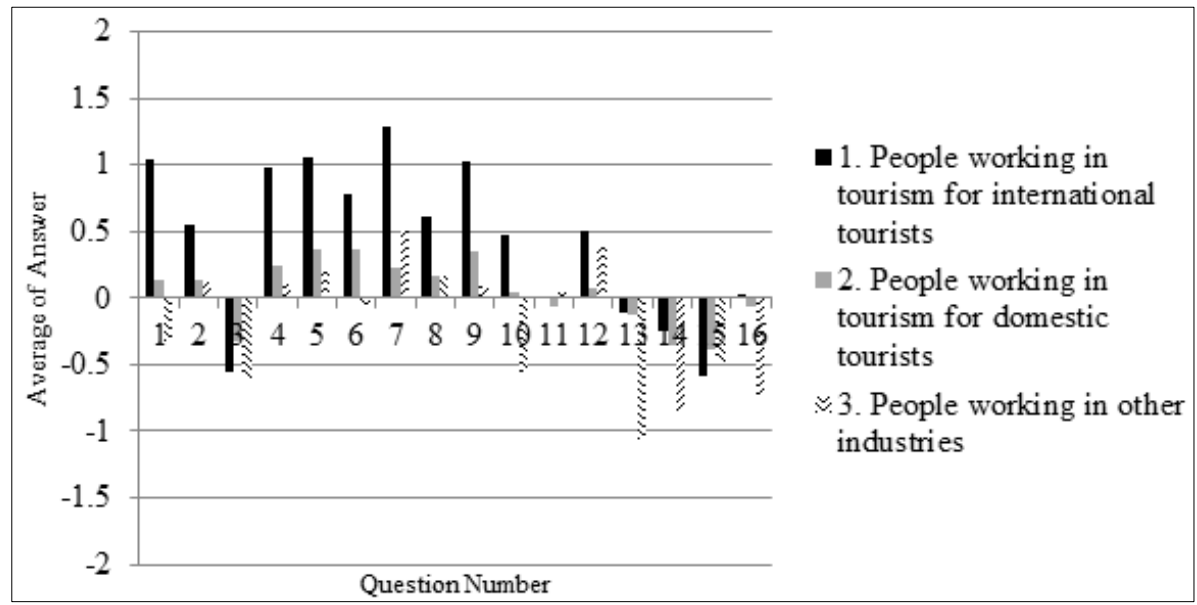

Figure 6. The average value section $2<$ it is effect from tourism $>$ when we stratified into three categories 
Figures 5 and 6 show the results of the average value Section 2-change. The local residents feel that the influence of tourism development is the greatest, related to the economic and social viewpoints. It is thought that the local residents feel the development of infrastructure and economy as the first ripple effect of tourism development.

In the economic and social sectors, most values of international tourism are positive. Therefore, only people working for tourism targeting international tourists are feeling the ripple effects in the economic and social sectors. Regarding the people working for domestic tourism and other industries, they do not feel the ripple effect from tourism development.

Therefore, it is considered necessary to find a way to spread more ripple effects for many people working in various industries. Additionally, we asked whether local people have appropriate knowledge in order to receive the ripple effects. Figure 7 shows the results of the average value in Section 3 when it is stratified into three categories.

From Figure 7, two question items are found to have significant difference, Question 1 and 3. Question 1 is asking the degree of agreement for the statement: "Your hometown has special local products for tourists". The average value of domestic tourism is very low because it is thought domestic tourists come there for the purpose of seeing historical places and architecture from the result of Question statement 2: "Your home town has sightseeing spots of culture appealing to tourists". If many tourists are interested in special local products, the income of local people might increase. Question 3 is the question about whether the respondent knows mostly from which country the majority of tourists come from. The average value of workers in tourism for internationals is high and the others are low; therefore, the others seem not to understand that international tourists can be their future customers. In order to produce the products and services attractive to international tourists, they need to know about the preferences of international tourists. This can lead to more development of their hometown.

In order to directly draw opinions of local residents, Section 4 to 6 consisted of open-end questions. To analyze this section, the frequently appearing words and terms were targeted and counted.

Section 4 asked "What kind of benefit and damage do local people get from tourism development?" Again, the word frequency was calculated. Table 3 shows the most frequent words about "benefits from tourism development" based on each of the industries. Regardless of the industry, "increase", "income" and "economy" are frequently mentioned as benefits. It shows that many people feel the influence on the economy strongly. On the other hand, people working in the tourism industry for domestic tourists tended to respond "No / nothing", so it can be assumed that that they feel they do not receive enough benefits by the influence of tourism development. Asking "whether the changes near your hometown based on tourism development are felt?" in Section 2, most people working in the tourism industry for domestic tourists feel change, depending on the development of the tourism industry, but it seems that they have not benefited so much and could not explain clearly the benefits. Table 4 shows the most frequent words about "damage from tourism development" based on each of the industries. Regardless of people working in the various industries, "no/nothing" are the most frequently used words. Most Nepalese people do not feel the damage from tourism development. However, people working in the international tourism sector use the word "culture". It seems that westernization is progressing and Nepalese traditional culture is decreasing in the tourist spots for international tourists.

Section 5 asks, "What kind of ripple effects from tourism development do you feel?". The purpose of this question is to find what local people think about the ripple effects. Table 5 shows the most frequent words for Section 5. As the overall trend, the number of responses was small. In other words, we inferred that they couldn't answer the open-ended question, because local people may not be familiar with the ripple effects. There were many people who answered "education" in all three industries among the few opinions. In order to further enhance their lives, education and the importance of learning are identified as being crucial for them and their children.

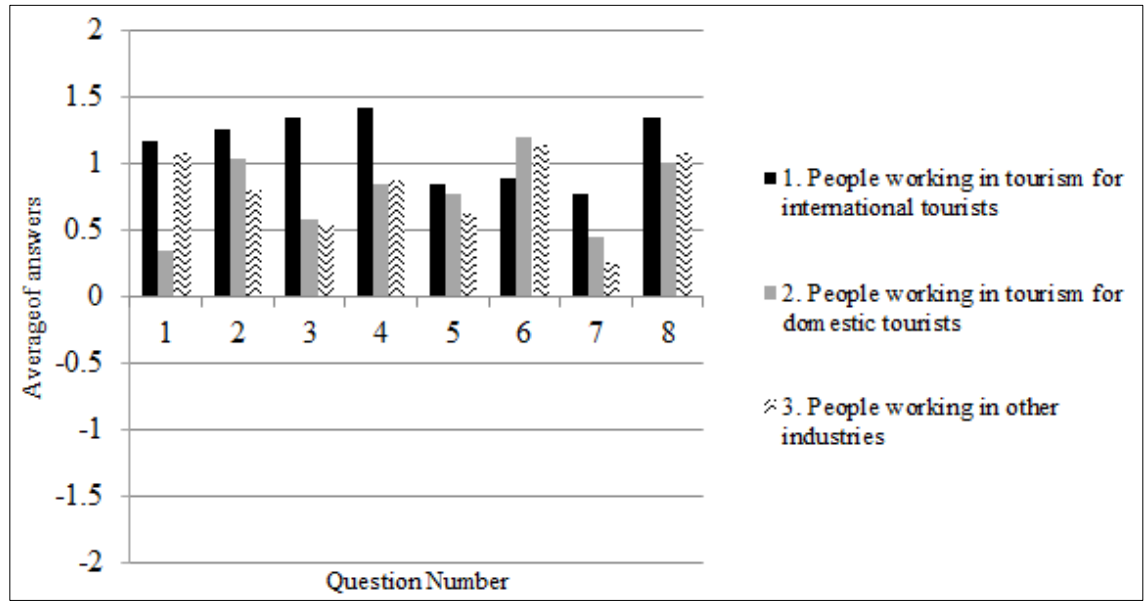

Figure 7. The average value Section 3 when we stratified into three categories 
Table 3. Three most frequent words by industry in Section 4-Benefit -

\begin{tabular}{|c|c|c|c|c|c|}
\hline \multicolumn{2}{|c|}{$\begin{array}{c}\text { 1. People working in tourism } \\
\text { for international tourists }\end{array}$} & \multicolumn{2}{c|}{$\begin{array}{c}\text { 2. People working in tourism } \\
\text { for domestic tourists }\end{array}$} & \multicolumn{2}{c|}{$\begin{array}{c}\text { 3. People working } \\
\text { in other industry }\end{array}$} \\
\hline terms & count & terms & count & terms & count \\
\hline increase & 59 & no/nothing & 19 & increase & 12 \\
\hline income & 28 & income & 11 & economic/economy & 10 \\
\hline business & 19 & increase & 10 & income & 7 \\
\hline
\end{tabular}

Table 4. Three most frequent words by industry in Section 4-Damage-

\begin{tabular}{|c|c|c|c|c|c|}
\hline \multicolumn{2}{|c|}{$\begin{array}{c}\text { 1. People working in tourism } \\
\text { for international tourists }\end{array}$} & \multicolumn{2}{|c|}{$\begin{array}{c}\text { 2. People working in tourism } \\
\text { for domestic tourists }\end{array}$} & \multicolumn{2}{c|}{$\begin{array}{c}\text { 3. People working } \\
\text { in other industry }\end{array}$} \\
\hline terms & count & terms & count & terms & count \\
\hline no/nothing & 59 & no/nothing & 28 & no/nothing & 12 \\
\hline culture & 22 & water & 3 & culture & 5 \\
\hline water & 5 & electricity & 3 & destroy & 3 \\
\hline
\end{tabular}

Table 5. Three most frequent words by industry in Section 5

\begin{tabular}{|c|c|c|c|c|c|}
\hline \multicolumn{2}{|c|}{$\begin{array}{c}\text { 1. People working in tourism } \\
\text { for international tourists }\end{array}$} & \multicolumn{2}{c|}{$\begin{array}{c}\text { 2. People working in tourism } \\
\text { for domestic tourists }\end{array}$} & \multicolumn{2}{c|}{$\begin{array}{c}\text { 3. People working } \\
\text { in other industry }\end{array}$} \\
\hline terms & count & terms & count & terms & count \\
\hline business & 12 & business & 8 & culture & 5 \\
\hline education & 9 & employment & 3 & education & 3 \\
\hline culture & 8 & hotel & 3 & hotel & 3 \\
\hline
\end{tabular}

Table 6. Three most frequent words by industry in Section 6

\begin{tabular}{|c|c|c|c|c|c|}
\hline \multicolumn{2}{|c|}{$\begin{array}{c}\text { 1. People working in tourism } \\
\text { for international tourists }\end{array}$} & \multicolumn{2}{c|}{$\begin{array}{c}\text { 2. People working in tourism } \\
\text { for domestic tourists }\end{array}$} & \multicolumn{2}{c|}{$\begin{array}{c}\text { 3. People working } \\
\text { in other industry }\end{array}$} \\
\hline terms & count & terms & count & terms & count \\
\hline skill & 20 & language & 8 & water & 16 \\
\hline road & 14 & water & 7 & skill & 11 \\
\hline language & 14 & clean & 6 & road & 9 \\
\hline
\end{tabular}

Table 7. Terms and frequency about language/skill in Section 6

\begin{tabular}{|c|c|c|c|}
\hline & $\begin{array}{c}\text { 1. People working in tourism } \\
\text { for international tourists }\end{array}$ & $\begin{array}{c}\text { 2. People working in tourism for } \\
\text { domestic tourists }\end{array}$ & $\begin{array}{c}\text { 3. People working } \\
\text { in other industry }\end{array}$ \\
\hline foreigner & 6 & 0 & 0 \\
\hline Chinese/Japanese & 8 & 0 & 0 \\
\hline write & 0 & 4 & 3 \\
\hline read & 1 & 2 & 3 \\
\hline
\end{tabular}

Table 8. The average value Section 7 when we stratified into three categories

\begin{tabular}{|c|c|c|c|}
\hline & $\begin{array}{c}\text { 1. People working in tourism } \\
\text { for international tourists }\end{array}$ & $\begin{array}{c}\text { 2. People working in tourism for } \\
\text { domestic tourists }\end{array}$ & $\begin{array}{c}\text { 3. People working } \\
\text { in other industry }\end{array}$ \\
\hline Average of answers & 1.88 & 1.76 & 1.62 \\
\hline
\end{tabular}

For the purpose of finding what to do to receive the ripple effects, the results of Section 6 are analyzed (Table 6). In all categories, people used the terms "water" or "road" in their answers. This result shows the importance of the maintenance of roads and their water supply. It is indispensable to maintain these infrastructures by the government. Similarly, in all categories, people pointed out the necessity of "skills" and "language". Therefore, the people are feeling the importance to know language or specific skills. However, the specific contents about language or skills are different, based on the industries. Table 7 shows the terms and their frequencies related with language and skill. From the answers by people working in international tourism, the terms "foreigner" or "Japanese/Chinese" are extracted. It means that they recognize the importance to sell their products and services to foreigners. From the answers of people working in domestic tourism or other industries, the terms "write" and 
"read" are extracted. It means that they think that their literacy education isn't sufficient. Without literacy, they cannot learn about the ripple effects from tourism.

Finally, we asked whether local people favor tourism development after considering the benefits and damage from the tourism industry through this questionnaire. Table 8 represents the results of Section 7, which indicates that Nepalese local people welcome tourism development. As a result, it can be said that the Nepalese government and society can put more emphasis on enriching the tourism industry in the future, as a means to develop their country.

\section{Suggestions}

Following these results, we have suggestions for the various sectors. First, for people working in international tourism, it is necessary to build knowledge of how to sell their products for tourists from abroad. If they could speak and write in the language of the people visiting, they can explain about their products. This leads to more sales. Second, there are three proposals for people working in domestic tourism. In order to attract more local visitors, it is necessary to promote the branding of local products and to improve reading and writing skills. To enhance the sites as sightseeing, it is important to know about the characteristics of international tourists. Additionally are the suggestions for people working in other industries. For individuals, improvements in writing and reading skills of basic Nepalese would be of benefit. This can ultimately lead to building knowledge on food sales.

Finally are the suggestions for the government and municipalities to spread the benefits from tourism. They should support social development, especially infrastructure and the water supply. This support has not been realized yet in Nepal. Additionally, the government and municipalities should support and develop the "local product branding". For example, they can create and implement a brand mark system for local producers. Lastly, it is necessary to know which products are in greatest demand for the purpose of developing the agriculture sector, or other sectors, which can benefit individuals at the local level.

\section{Conclusions}

In this survey, we investigated the consciousness of local residents about ripple effects from tourism development, focusing on differences between industries. Through the results of our field survey, we clarified the differences and the knowledge for receiving ripple effects between the primary ripple effect to people engaged in the tourism industry and the second ripple effect to those engaged in tourism. Meanwhile, irrespective of whether it engages or not, it became clear that the tourism industry was favorably developing. We suggested how to spread the ripple effects from tourism development in Nepal. We gave suggestions for the various different sectors and how it is important for different sectors to be collaborative towards tourism development in order to benefit from the ripple effects of tourism. One way suggested are measures, such as "local product branding".

In addition, it is possible to conduct similar investigations in developing countries and regions that are similar to Nepal. When applying the survey method which we conducted in this research, it may be possible to clarify the differences and influences by tourism development between industries.

In future, there are two aspects we would like to investigate. One is to investigate the consciousness of people in various industries, especially those receiving the first ripple effects. Second is to focus on the money flow from the ripple effects of tourism.

\section{Acknowledgements}

We are very grateful to experts for their appropriate and constructive suggestions to improve this research paper. The authors would like to acknowledge Mr. Ujjwal Upadhyay, National College, Kathmandu, Mr. Shuji Yagyu, Graduate University for Advanced Studies, and Ms. Manita Shresta, Kanagawa Committee for UNICEF, for their useful suggestions and cooperation for our research. In addition, we are very grateful to Ms. Ayako Yamagiwa, Waseda University, Ms. Yu Sugiyama, University of Sacred Heart and the members of Nepal Japan Project team, for their helpful comments for this research. A part of this study was supported by JSPS KAKENHI Grant Numbers 25301002.

\section{REFERENCES}

[1] T. Brijesh. Tourism in Nepal: Shangri-La's troubled times, Journal of Travel and Tourism Marketing, Vol.15, No.2,3, 117-138, 2004.

[2] K. Bhattarai, D. Conway, N. Shrestha. Tourism Terrorism and Turmoil in Nepal, Annals of Tourism Research, Vol. 32, No. 3, 669-688, 2005.

[3] Y. Nishihara, N. Fujiwara, M. Goto, B. Bushell. A survey for sustainable development of tourism in Nepal, Interdisciplinary Environment Review, Vol. 15, No. 4, 239-251, 2014.

[4] M. Hart. Guide to Sustainable Community Indicators, Community Development Institute, Hartford, Connecticut, 2006.

[5] A. J. Garcia, M. Gomez, A. Molina. A destination-branding model: An empirical analysis based on stakeholders, Tourism Management Marcello. Vol. 33, No. 3, 646-611, 2012.

[6] D. N. Sutihar. An Analysis of Religious Tourist Growth in Nepal, Economic Literature Vol. 11, 20-25, 2016.

[7] K. R. Dhakal. An Analysis of the Tourism in Nepal Trend of Tourist Arrivals. The Third Pole: Journal of Geography Education, Vol. 13, 46-53, 2014. 
[8] J. Poudel. Socio-Cultural Impact in Tourism: A Case Study of Sauraha, Nepal. Journal of Advanced Academic Research, Vol. 1, No. 2, 47-55, 2017.

[9] H. L. Ghimire. Tourism in Gorkha: A proposition to Revive Tourism after Devastating Earthquakes. Journal of Tourism and Hospitality Education, Vol. 6, 67-94, 2016.

[10] R. R. Kunwar, U. Chand. Natural Disaster and Heritage Tourism: A Study on the Impacts of Earthquake in Bhaktapur, Nepal. Journal of Tourism and Hospitality Education, Vol. 6 $1-39,2016$.

[11] M. Apollo. The clash-social, environmental and economical changes in tourism destination areas caused by tourism the case of Himalayan villages (India and Nepal), Current Issues of Tourism Research, Vol. 5, No. 1, 6-19, 2016.

[12] K. C. Anup, R. B. T. Parajuli. Tourism and its impact on livelihood in Manaslu conservation area, Nepal. Environment, development and sustainability, Vol. 16, No. 5, 1053-1063, 2014.

[13] B. Rani, E. Templin, C. Messer, S. Chazdon. Participatory evaluation and learning: a case example involving ripple effects mapping of a tourism assessment program. Journal of Extension Vol. 55, No. 2, 2017.

[14] H. Zhang, O. M. Ghoochani, B. Pan, J. Crotts. A Case Study on the Impact of Personal Characteristics on Residents' Support for Tourism Development, Tourism travel and research association international conference, 2016.

[15] A. Scaglione, D. Mendola. Measuring the perceived value of rural tourism: a field survey in the western Sicilian agritourism sector, Quality \& Quantity, Springer, Vol. 51, No. 2, 745-763, 2017.

[16] R. Turner, E. Freiermuth. Travel and Tourism Eonomic Impact 2017 Nepal, World Travel \& Tourism Council Algorithmic Musical Composition, 2017.
[17] A. I. Elaine, C. A. Seaman. Likert scales and data analyses, Quality progress, Vol. 40, No. 7, 64-65, 2007.

[18] L. Jiaying, S. K. Nepal. Sustainable tourism research: An analysis of papers published in the Journal of Sustainable Tourism, Journal of Sustainable Tourism, Vol. 17, No. 1, 5-16, 2009.

[19] B. P. Gautam. Tourism and economic growth in Nepal. NRB Economic Review, Vol. 23, No. 2, 18-29, 2011.

[20] D. N. Zurick. Adventure travel and sustainable tourism in the peripheral economy of Nepal, Annals of the Association of American Geographers, Vol. 82, No. 4, 608-628, 1992.

[21] V. Adams. Tourism and Sherpas, Nepal: reconstruction of reciprocity, Annals of tourism research, Vol. 19, No. 3, 534-554, 1992.

[22] G. P. Nyaupane, T. Brijesh. Perceptions of environmental impacts of tourism: A case study at ACAP Nepal, The International Journal of Sustainable Development and World Ecology, Vo. 13, No. 1, 51-61, 2006.

[23] K. K. Karanth, S. K. Nepal. Local residents perception of benefits and losses from protected areas in India and Nepal, Environmental management, No. 49, Vol. 2, 372-386, 2012.

[24] S. K. Nepal. Traditions and trends: A review of geographical scholarship in tourism, Tourism Geographies, Vol. 11, No. 1 2-22, 2009.

[25] P. K. Upadhayaya, U. Müller-Böker, and R. S. Sagar, Tourism amidst armed conflict: Consequences, copings, and creativity for peace-building through tourism in Nepal, The Journal of Tourism and Peace Research, Vol. 1, No. 2, 22-40, 2011.

[26] Kathmandu post, Tourism pumped Rs177b into Nepal's economy, On available from http://kathmandupost.ekantipur.com/news/2017-03-31/touris m-pumped-rs177b-into-nepals-economy.html 